\title{
Patent DuctusArteriosus Treatment: Size does Matter
}

\author{
Suraj Wasudeo Nagre* and Krishnarao Narayanrao Bhosle \\ Department of CVTS, Grant Medical College, Mumbai, India
}

\begin{abstract}
Patent DuctusArteriosus ( PDA ) is one of the commonest acyanotic congenital heart disease. Surgical or device closure is done when medical management fails. Choice of management depends on size of PDA. A study was conducted to assess the type of surgical technique to be followed either direct ligation or division and suturing. 10 Cases of PDA were studied from May 2012 to May 2017 ages ranged from 12 days to five years with youngest weighing 650 grams. There were no postoperative complications and death. In two patients division suturing done and in other eight ligation was done. Repeat $2 \mathrm{D}$ echo after three months did not show recanalization in either group. Conclusion was both techniques are equally effective but division suturing was more difficult than ligation.
\end{abstract}

Keywords: PDA-Patent Ductusarteriosus DA-Ductusarteriosus

\section{Introduction}

Patent DuctusArteriosus ( PDA ) is one of the commonest acyanotic congenital heart disease. Failure of the ductusarteriosus (DA) to close within 72 hours after birth result in PDA. Clinical signs of ductal patency are murmur, tachycardia, bounding peripheral pulses, and congestive heart failure. Complications of a persistently patent DA after birth are heart failure, renal dysfunction, necrotizing enterocolitis (NEC) and altered postnatal nutrition and growth $^{[1,3]}$. Also risk of developing of chronic lung disease. Pharmacologic closure can be done by administration of intravenous indomethacin or ibuprofen. Surgical or device closure is done when medical management fails. Choice of management depends on size of PDA. A study was conducted to assess the type of surgical technique to be followed either direct ligation or division and suturing.

\section{Material and Method}

Ten cases of PDA were studied from May 2012 to May 2017. All procedures performed in studies involving human participants were in accordance with the ethical standards of the institutional and/or national research committee and with the 1964 Helsinki declaration and its later amendments or comparable ethical standards. All patients were operated with limited posterolateral thoracotomy. Of which two were taken for division and suturing [Figure 1] and eight underwent ligation[ Figure 2]. Size of PDA at pulmonary artery end was the determinant in deciding the type of technique. 5 or more than $5 \mathrm{~mm}$ was considered for division and suturing. Less than $5 \mathrm{~mm}$ was considered for ligation. $40 \%$ of the patients were females. The ages ranged from 12 days to 5 years with youngest weighing 650 grams. Time required for division and suturing was one hour as compared to just forty minutes for ligation of PDA. There were no immediate or late postoperative deaths. There were no intraoperative or postoperative complications. The mean hospital stay was three days. Repeat $2 \mathrm{D}$ echo after three months did not show recanalization in either group.

\section{Discussion}

The device closure of PDA can be done safely in infants $>3.5 \mathrm{~kg}$, and can currently close PDAs of upto 11 to $12 \mathrm{~mm}$ in minimum diameter ${ }^{[5,7]}$. Nagre $\mathrm{S} \mathrm{W}$ has discussed management approach of ASD as well PDA in his studies ${ }^{[2,4,6,8]}$. The device combines ease of use, including retrievability and repositioning when required, and a high occlusion rate $(>99 \%$ complete occlusion of PDA within 6 months of implant, with the majority of occlusions occurring within 24 hours of implant) ${ }^{[0]}$. Possible complications, such as device embolization ${ }^{[10]}$, protrusion of the retention disc of the device into the aorta producing aortic obstruction, or obstruction of a branch pulmonary artery by the device are also uncommon and can be avoided by choosing the appropriate sized device (with the pulmonary end of the device being $2 \mathrm{~mm}$ larger in diameter than the minimum measured ductal diameter), and paying scrupulous attention to technique of deployment. Surgical management is reserved for patients who cannot be managed pharmacologically and by cath intervention. Surgical repair of a PDA typically involves either ligation or division and suturing via left posterior lateral thoracotomy. Division suturing requires more time than simple ligation of PDA. Division suturing was more difficult with risk of complications than simple ligation of PDA.

\section{Conclusion}

Most children can have the PDA closed by pharmacological management specially premature infants, some may require cath intervention and device or coil closure. In surgical 


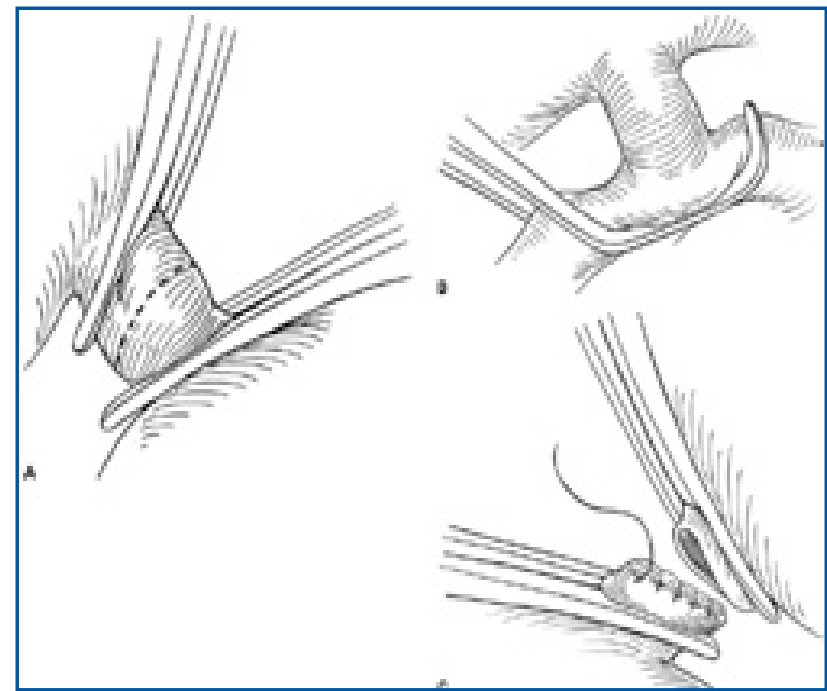

Fig. 1: PDA Division and Suturing.

management ligation as well as division and suturing both techniques are equally effective but division suturing was more difficult and time consuming than ligation.Simple ligation of PDA becomes treatment of choice whenever medical management fails and device closure not possible. However larger ,long follow up and a multi centric study is required to set up a definitive guidelines.

Consent-Informed consent has been obtained

Funding-no funding was required for this study

Conflict of Interest-No potential conflict of interest exist

Ethical approval: All procedures performed in studies involving human participants were in accordance with the ethical standards of the institutional and/or national research committee and with the 1964 Helsinki declaration and its later amendments or comparable ethical standards.

\section{References}

1. Gittenberger-de Groot AC, Moulaert AJ, Hitchcock JF. Histology of the persistent ductusarteriosus in cases of congenital rubella.Circulation. 1980;62:183-186.

2. Nagre SW (2016) Atrial Septal Defect: Management Approach in Children. Ann Woman Child Health 2: 3-4

3. Pegoli W. Pericardium and great vessels. In: Oldham KT, Colombiani PM, editors. Principles and Practice of Pediatric

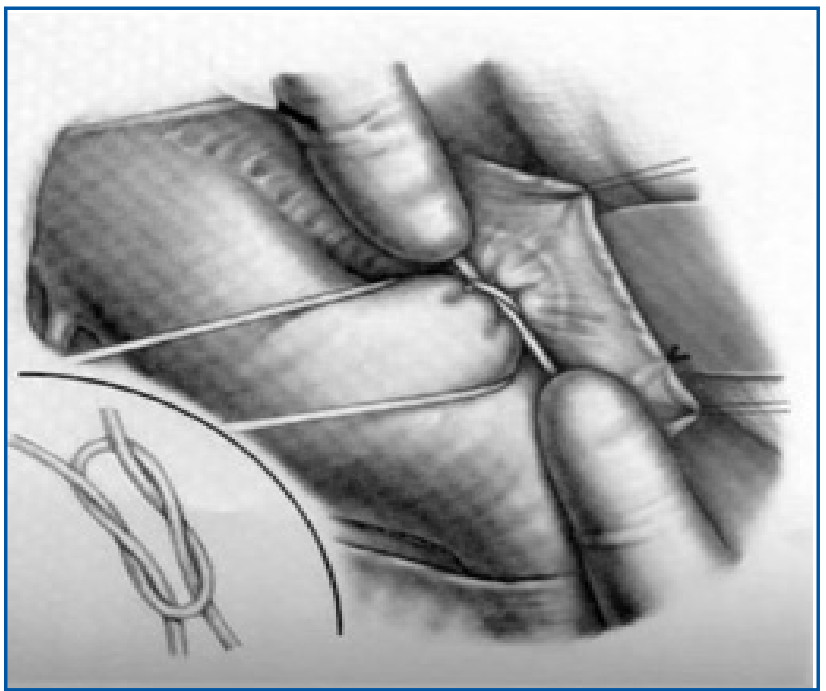

Fig. 2: PDA Ligation.

Surgery. 4th ed. Philadelphia, PA: Lippincott Williams \& Wilkins; 2005. p. 1019.et al., editors.

4. Management of Patent DuctousArteriosus -Short Review ,Annals of Woman and Child Health, Vol. 2; Issue 4: 2016,Nagre S W

5. Miao CY, Zuberbuhler JS, Zuberbuhler JR. Prevalenceof congenital cardiac anomalies at high altitude. J AmCollCardiol. 1990;12:224-228.

6. Nagre SW, Nagre MS (2015) Observational Study of Surgical Closure of OstiumPrimum Atrial Septal Defect in Thirty Paediatric Patients. Ann Woman Child Health 1: 1-4

7. Nora JJ, Nora AH. Recurrence risks in children havingone parent with a congenital heart disease. Circulation. 1976;53:701-702.

8. NagreSW(2017) Atrial Septal Defect - Forgotten Treatment Guidelines. Acute Chronic Diss 1: e101.

9. Pezzati M, Vagni V, Biagiotti R. Effects of indomethacinand ibuprofen on mesenteric and renal blood flow inpreterm infants with patent ductusarteriosus. J Pediatr.1999;135:733-738. et al.

10. Surgical removal of embolised atrial septal defect device from pulmonary artery, The Journal of thoracic and cardiovascular surgery, ISSN: 1097-685X, Vol: 150, Issue: 4, Page: e55-7 Publication Year: 2015 , http://dx.doi. org/10.1016/j.jtcvs.2015.07.040

*Corresponding author:

Dr. Suraj Wasudeo Nagre, 31,TrimurtiBuilding,J J Hospital compound, Byculla , Mumbai, Pin -400008

Phone: +91 9967795303

Email: surajnagre@yahoo.com

Financial or other Competing Interests: None.

Date of Submission : 05.12.2017

Date of Acceptance : 12.12.2017

Date of Publication : 15.12.2017 